\title{
Controlled Release of Acyclovir Through Bioengineered Corneal Implants with Silica Nanoparticle Carriers
}

\author{
Bettina Bareiss ${ }^{1,2}$, Masoud Ghorbani ${ }^{3}$, Fengfu Li ${ }^{1,2}$, Jessie A. Blake ${ }^{4}$, Juan C. Scaiano ${ }^{4}$, \\ Jin Zhang ${ }^{1,2}$, Chao Deng ${ }^{1,2}$, Kimberley Merrett ${ }^{1,2}$, James L. Harden ${ }^{5}$, Francisco Diaz-Mitoma ${ }^{3, \S}$ \\ and May Griffith ${ }^{*},, 1,2$ \\ ${ }^{1}$ University of Ottawa Eye Institute, Ottawa, Ontario, Canada \\ ${ }^{2}$ Dept. of Cellular and Molecular Medicine, University of Ottawa, Ottawa, Ontario, Canada \\ ${ }^{3}$ Dept. of Virology, Children's Hospital of Eastern Ontario, Ottawa, Ontario, Canada \\ ${ }^{4}$ Dept. of Chemistry, University of Ottawa, Ottawa, Ontario, Canada \\ ${ }^{5}$ Dept. of Physics, University of Ottawa, Ottawa, Ontario, Canada
}

\begin{abstract}
Herpes simplex virus (HSV) infection is the most common cause of corneal blindness in the Western world. Despite effective anti-viral drugs such as acyclovir (ACV), disease recurrence due to the virus establishing latency within the corneal nerves and possibly cells makes treatment very challenging. Furthermore, although effective, current systemic and topical preparations of anti-viral drugs do not appear to deliver sufficient quantities to the cornea to prevent reactivation. Current treatment for HSV vision loss is transplantation with donor corneas, but the surgery itself can reactivate viruses. We examined the feasibility of preventing viral reactivation during surgery, by sustained delivery of ACV introduced during corneal transplantation surgery, through encapsulation of the drug within silica $\left(\mathrm{SiO}_{2}\right)$ nanoparticles (NP) incorporated into biosynthetic alternatives to donor corneas. We show that incorporation of NPs did not affect optical clarity of the collagen-based corneal substitutes nor their biocompatibility. NP-encapsulation effectively sustained ACV release from the biosynthetic implants over 10 days, compared to free ACV incorporated directly into the hydrogel constructs. The NP-enabled sustained release resulted in effective prevention of virally-induced cell death, not observed with the free drug. This early model demonstrates the feasibility of using biomimetic corneal substitutes that incorporate a drug release system (e.g. silica nanoparticles encapsulating ACV) as future alternatives to human donor tissue grafts, for transplantation of HSV-infected corneas.
\end{abstract}

Keywords: Acyclovir, bioengineered corneal substitutes, herpes simplex virus, nanoparticles, drug delivery.

\section{INTRODUCTION}

The Herpes simplex virus (HSV) is a neurotrophic virus that commonly infects the skin and mucous membranes of the mouth, genitalia, and eye. HSV-1 is the strain most commonly associated with corneal infections, and is the major cause of infectious vision loss in the developed world. Approximately 500,000 cases of corneal HSV infections are reported yearly in the US alone. There are 50,000 new and recurrent cases per year [1-4], with visual disability reported as high as $40 \%$ [5]. The pathogenesis for HSV infection is complex. Initial exposure generally results in a primary infection that can give rise to a variety of clinical symptoms. Symptoms can include surface (epithelial) ulceration and nerve damage, damage to deep stromal structures, corneal perforation, and both necrotizing and non-necrotizing stromal disease. Following recovery from primary infection,

*Address correspondence to this author at the University of Ottawa Eye Institute, Ottawa, Ontario, Canada; Tel: (613) 737-8822; Fax: (613) 6392720; E-mail: mgriffith@ohri.ca

${ }^{\S}$ Indicate equivalent contributions the virus establishes latency in the trigeminal ganglion that supplies sensory neurons to the ocular surface [6] and likely, within the cornea [1]. The total viral load of HSV-1 genomes in the trigeminal ganglia during latency was reported to be between 1,000 to 10,000 copies [7]. Shimomura (2007) reported that corneas with a history of HSV keratitis harbor $1.6 \times 10^{4}$ copies of HSV DNA [8]. Triggers for reactivation are varied and non-specific, and can include stress, immunosuppression, sunlight, and ingestion of certain foods [2].

Corneal transplantation is the treatment of choice for $\mathrm{HSV}$-induced corneal blindness that results from opacity due to heavy corneal damage and scarring [5]. However, prognosis is very poor with a low success rate at five years [3] due to viral reactivation and infection of grafts compared to non-HSV grafts [5]. We have previously developed corneal stromal matrix substitutes, based on carbodiimidecrosslinked recombinant human collagen, that are biointeractive. These substitutes promoted regeneration of corneal epithelial and stromal layers, as well as corneal nerves in pig models [9, 10]. Early results from an on-going Phase I clinical study shows similar results in humans [11]. Furthermore, an acellular scaffold implant decreased postoperative inflammation, eliminating the need for sustained 
steroidal use when compared to allograft transplants [11]. More recently, we enhanced the mechanical strength and biostability of such collagen hydrogels by incorporating a second crosslinked polymeric network based upon a synthetic phospholipid, 2-methacryloyloxyethyl phosphorylcholine (MPC). These interpenetrating networks of collagen showed an increase in mechanical strength over crosslinked collagen alone, and an increased stability against enzymatic degradation while retaining their ability to promote regeneration of both corneal cells and nerves [12]. The increased stability in a hostile environment of high enzymatic activity commonly found in HSV-infected corneas is important for implant retention and viability.

Acyclovir (ACV) is an anti-viral drug that is used both topically and orally to treat ocular HSV. It is a nucleotideanalogue that is specifically activated by HSV-induced thymidine kinase, and inhibits viral DNA polymerase. Noninfected cells are not affected by ACV, as they have no means of activating the drug $[6,13]$. While oral ACV is an effective drug against HSV-1 infections [14, 15], it is expensive, and long term use can lead to gastrointestinal upset, as well as suppression of the immune system $[14,16]$. To bypass these problems, ACV can be administered through eye drops. This delivery method demonstrates low efficacy, due to poor drug solubility and lack of penetration to the target sites [14, 17, 18]. Topical delivery of ACV through colloidal systems such as encapsulated nanoparticles, microparticles, and lipsomes, has improved the delivery of this drug to some degree [19-21]. Efficacy is still limited as the product is quickly discharged from the eye (i.e. by blinking or tears) [14]. Placing the drug carrier within a stable hydrogel, such as a contact lens therefore allows sustained delivery [17]. It therefore follows that a stable hydrogel, such as our collagen-MPC interpenetrating networks that has been developed as a corneal substitute for transplantation, can also serve as a drug carrier. In the case of high risk transplants of HSV-infected eyes, drugs such as ACV could be included within the implant to treat or circumvent HSV-reactivation triggered by the surgery.

In this study, we tested the hypothesis that a nanoparticulate drug delivery system, delivering ACV for example, can be incorporated into our corneal substitutes and can inhibit HSV infection. Such ACV containing corneal substitutes will be suitable for high risk transplant patients with latent HSV, aiding in the prevention of HSVreactivation triggered by the surgery.

Silica $\left(\mathrm{SiO}_{2}\right)$ nanoparticles $(\mathrm{NP})$ (diameter $\left.<100 \mathrm{~nm}\right)$ were selected as a prototype delivery vehicle, as they are simple to prepare and a range of methods for preparing porous $\mathrm{SiO}_{2} \mathrm{NP}$ are available [14, 22-28]. The microemulsion and reversed micelle (with $\mathrm{HCl}$ ) method [29-31] was selected, as the water-oil microemulsion effectively encapsulates hydrophobic drugs (such as ACV), by dissolving the drug in the oil phase [17]. We examined the effects of encapsulation of ACV within $\mathrm{SiO}_{2} \mathrm{NP}$ on drug activity. We compared the release kinetics of $\mathrm{ACV}$ from NP within collagen-MPC hydrogels, with release of free ACV within similar hydrogels. With respect to their implications in the prevention of HSV-1 re-infection, we demonstrate that the sustained release of NP encapsulated ACV within hydrogels was able to prevent re-infection of corneal cells in culture.

\section{MATERIALS AND METHODOLOGY}

\section{Materials}

Type I porcine atelocollagen was purchased from Nippon Meat Packers Inc. (Tokyo, Japan). Poly(ethylene glycol) diacrylate (PEGDA, $\left.\mathrm{M}_{\mathrm{n}}=575\right)$, 1-ethyl-3-(3-dimethylaminopropyl) carbodiimide (EDC), ACV, Cyclohexane, tetraethyl orthosilicate (TEOS), 2,2-dimethyl methoxy-2-phenyl acetophenone (DMPA), ammonium persulfate (APS), N,N,N',N'tetramethyl ethylene diamine (TEMED) and Triton were purchased from Sigma-Aldrich Canada Ltd (Ontario, Canada). 2-animoethyl methacrylate (AEMA) was purchased from PolySciences Inc (PA, USA). N-hydroxyl-succinimide (NHS) was purchased from Fluka (Buchs, Switzerland). 2 methacryloyloxyethyl phosphorylcholine (MPC) was purchased from Biocompatibles UK Ltd (Surrey, UK). All chemicals, unless otherwise stated, were obtained from Sigma-Aldrich Canada Ltd (Ontario, Canada).

\section{Preparation of Silica Nanoparticles and Acyclovir Encapsulation}

For preparation of $\mathrm{SiO}_{2} \mathrm{NP}, 6 \mathrm{ml}$ cyclohexane was combined with $2 \mathrm{ml}$ Triton, followed by the addition of a solution of $1.5 \mathrm{ml}$ concentrated hydrochloric acid containing $80 \mathrm{mg}$ ACV. Under magnetic stirring, $0.5 \mathrm{ml}$ TEOS was added drop wise, followed by slow neutralization of the mixture using concentrated ammonia hydroxide. The mixture was stirred for two days at $50{ }^{\circ} \mathrm{C}$. The resulting NPs were washed twice with $50 \%$ ethanol, and then vacuum dried. For controls, $\mathrm{SiO}_{2} \mathrm{NP}$ were prepared as above, but w8 ithout the addition of ACV. The concentration of free ACV in solution was measured at $252 \mathrm{~nm}$ with a Beckman Du-640B spectrophotometer. Particle size and morphology of resultant particles were determined on a Phillips CM120 Transmission Electron Microscope (TEM).

\section{Biocompatibility of Silica Nanoparticles}

Immortalized human corneal epithelial cells (HCEC) that possess key morphological and physiological characteristics of primary cells [32] were grown to $80 \%$ confluence in 48well plates supplemented with Keratinocyte Serum-Free Medium (KSFM; Invitrogen, Burlington, Canada) in a humidified tissue culture incubator. ACV, $\mathrm{SiO}_{2}$, or $\mathrm{SiO}_{2}$ encapsulated ACV at concentrations of $0,10,25,50,100$, 250 and $500 \mu \mathrm{g} / \mathrm{ml}$ were introduced into the culture medium and incubated for 24 hours. Cytotoxicity was tested using live/dead staining (Molecular Probes kit) and a MTT assay [33].

To determine whether there was any uptake of NP by HCEC, cells were incubated for 24 hours with $100 \mu \mathrm{g} / \mathrm{ml}$ NPs. They were released from the dishes by light typsinization, pelleted by centrifugation, rinsed and then fixed in $2 \%$ glutaraldehyde in $0.1 \mathrm{M}$ phosphate buffered saline (PBS). They were then processed for transmission electron microscopy (TEM) according to standard procedures at the electron microscopy facility at the Children's Hospital of Eastern Ontario (CHEO) in Ottawa. Samples were examined and micro-graphed using a JEOL 1010 transmission electron microscope. 


\section{Collagen-MPC Hydrogels}

Collagen-MPC hydrogels were prepared as previously described [12]. Briefly, $400 \mathrm{mg}$ of $20 \%(\mathrm{w} / \mathrm{w})$ porcine type I acidic atelocollagen solution was buffered with $150 \mu 1$ of $0.625 \mathrm{M}$ MES buffer in a syringe mixing system. The solution was thoroughly mixed with $100 \mu 1$ of $20 \%(\mathrm{w} / \mathrm{v})$ MPC solution in MES buffer, before adding $6 \mu 1$ PEGDA solution. $25 \mu 1$ of $4 \%(\mathrm{w} / \mathrm{v})$ APS solution in MES buffer containing TEMED (APS:TEMED $=1: 0.78, \mathrm{w} / \mathrm{w}$ ) was added into the collagen-MPC-PEGDA solution and thoroughly mixed at $0{ }^{\circ} \mathrm{C}$. Calculated volumes of EDC and NHS solution (both at $20 \% \mathrm{w} / \mathrm{v}$, molar equivalent ratio EDC:NHS:collagen- $\left.\mathrm{NH}_{2}=1.5: 1.5: 1\right)$ were then added to crosslink the collagen and again thoroughly mixed at $0{ }^{\circ} \mathrm{C}$. The final mixture was immediately dispensed into glass plate moulds. The hydrogels were cured at $100 \%$ humidity under nitrogen at room temperature for $16 \mathrm{~h}$, and then at $37{ }^{\circ} \mathrm{C}$ for $5 \mathrm{~h}$ prior to demoulding in a $0.1 \mathrm{M}$ phosphate buffered saline (PBS) solution.

\section{Effect of Incorporation of Silica Nanoparticles on Hydrogel Optical Properties}

Light transmission through hydrogels was measured on a custom-built instrument previously described [34]. The measurements were made at $21^{\circ} \mathrm{C}$. Readings were obtained both for white light (quartz-halogen lamp source) and for narrow spectral regions (centered at $450,500,550,600$, and $650 \mathrm{~nm})$.

\section{Preparation of Hydrogels Containing Nanoparticle- Encapsulated or Free Acyclovir}

To incorporate ACV into collagen-MPC gels, $300 \mu \mathrm{l}$ ACV solution $(0.2 \mathrm{mg} \mathrm{ACV}$ in $0.3 \mathrm{ml}$ water) was added to the hydrogel solution prior to addition of APS to cure. To incorporate NP encapsulated ACV, $300 \mu \mathrm{ACV} \mathrm{SiO}_{2} \mathrm{NP}$, (5.31 mg ACV SiO $2 ~ N P$, in $0.3 \mathrm{ml}$ water) was added to the mixture prior to APS curing.

\section{Acyclovir Release and Bioactivity of Released Drug}

Hydrogels containing either ACV or $\mathrm{SiO}_{2} \mathrm{NP}$ encapsulated ACV were placed in $15 \mathrm{ml}$ PBS for 12 days and assayed for amounts of drug released. On Days 1, 2, 3, 6, 8, 10 and 12, the PBS was collected and replaced by fresh PBS. All PBS time points were analysed by high performance liquid chromatography (HPLC). HPLC was performed using an Agilent 1100 Series apparatus (G1379A Degasser, G1312A Binary Pump, G1387A Autosampler, G1315B Diode Array Detector). Separations were achieved on a reversed-phase C-18 column (Zorbax SB C-18 $4.6 \mathrm{~mm}$ x 25 $\mathrm{cm})$ at room temperature. The mobile phase, flowing at a rate of $0.5 \mathrm{~mL} / \mathrm{min}$., consisted of acetonitrile and water with $1 \%$ acetic acid added to improve peak shape. It was ramped from $0 \%$ to $50 \%$ acetonitrile over $25 \mathrm{~min}$., then to $100 \%$ acetonitrile over $20 \mathrm{~min}$., then back to $100 \%$ water with acetic acid over $10 \mathrm{~min}$. with a final 5 minutes at this composition. The injection volume was $10.0 \mu \mathrm{l}$. Absorbance signals were monitored at $254 \mathrm{~nm}$ using $400 \mathrm{~nm}$ as a baseline reference. Under these conditions, acyclovir was detected at $11.9 \mathrm{~min}$. and was sufficiently separated from the background peaks. Quantification was based on peak area using a calibration curve constructed by analyzing standard samples of ACV with the identical HPLC method.

To confirm the bioactivity of the released ACV, the ability of the released drug to block the cytopathogenic effects of HSV-1 viruses was compared to that of free drug. Briefly, $2.5 \times 10^{4}$ HCECs were seeded onto 12-well tissue culture plates as previously described and incubated until confluence. $10^{4} \mathrm{pfu} /$ well of HSV-1 was added, along with free ACV at concentrations of $0.5,1.0,2.0$ and $4.0 \mu \mathrm{g} / \mathrm{ml}$; or $\mathrm{SiO}_{2} \mathrm{NP}$ encapsulated ACV at concentrations of $0.5,1.14$, 2.28 and $3.5 \mu \mathrm{g} / \mathrm{ml}$. After 24 hours, the cultures were fixed with $80 \%$ acetone and stained with crystal violet. Infected cells that were dead (or showed gross cytopathic changes) vs healthy, live cells were counted in four randomly selected areas in the field of view for each sample and proportions of infected cells were noted ( $\mathrm{n}=6$ samples for each condition). Difference in proportions of infected vs. healthy cells at each dose range was analyzed by ANOVA, followed by a Tukey test, with statistical significance set at $\mathrm{P}<0.05$.

\section{Efficacy of Released ACV in Preventing Re-infection over 12 days}

Collagen-MPC gels containing either free ACV or $\mathrm{SiO}_{2}$ NP encapsulated ACV were placed on top of HECE cell cultures of $80 \%$ confluence, allowing for release of the drug. After time points Day 1, Day 2, Day 3, Day 6, Day 8, Day 10 and Day 12, HSV-1 viruses were added to the HCEC cultures at a ratio of $0.1 \mathrm{MOI}\left(10^{4} \mathrm{pfu} \mathrm{HSV}\right)$ to simulate viral re-infection (or re-activation). The cells, viruses, and hydrogel samples were re-incubated for a further 48 hours, after which all samples were fixed in $80 \%$ acetone and stained with crystal violet ( $\mathrm{n}=6$ samples for each condition). Uninfected cells and virus-infected but untreated cells served as controls. Cultures were imaged on a Nikon inverted microscope, and proportions of live to dead cells (including cells with gross cytopathic changes) were counted from an average of four randomly selected areas of each sample. Differences in ACV release efficacy, as indicated by the proportion of live cells, were analyzed statistically, using a one-way ANOVA. Statistical significance was set at $\mathrm{P}<$ 0.05 .

\section{Efficacy of Released ACV in Reducing Viral Copies in Treated Cells: Real-Time Reverse Transcription PCR (qRT-PCR)}

Total RNA was extracted from four different HCEC samples, using a RNeasy mini kit (Qiagen) after 3 days of infection. The samples comprised HCEC infected with $10^{4}$ pfu HSV-1 that were untreated, treated with hydrogel containing ACV only, or treated with hydrogel containing $\mathrm{SiO} 2 \mathrm{NP}$ encapsulated $\mathrm{ACV}$; and a negative control of uninfected cells. Reverse transcription of total RNA was performed using a SMART ${ }^{\mathrm{TM}}$ PCR cDNA Synthesis Kit (Clontech) to generate cDNA, according to the manufacturer's instructions. qRT-PCR was performed in special optical tubes in 96-well microtitre plates (Perkin-Elmer/ Applied Biosystems) using an iCycler (Bio-Rad). Fluorescent signals were generated using a Quantitect SYBR Green PCR kit (Qiagen). Glyceraldehyde-3-phosphate dehydrogenase (GAPDH), a stably expressed housekeeping gene was used to normalize HSV gene expression. GAPDH sense and 
antisense primer sequences used were: 5-ATGTGTCCGT CGTGGATCTGA-3 and 5-TTGAAGTCGCAGGAGACA ACCT-3, respectively. The HSV gene was analyzed using $\mathrm{HSV}-1$ sense and antisense primer sequences 5-CCGTCAG CACCTTCATCGA-3 and 3-CTGATGTGCCTCCAGGTC GC-5 obtained from the diagnostic laboratory at CHEO. The HSV and GAPDH genes were amplified using the abovementioned primers and a cDNA template from the four different groups. Target samples were added in individual reactions to a total volume of $25 \mu \mathrm{l}$ and no cDNA was added to the negative control. For each amplification using realtime PCR, the protocol included $10 \mathrm{~min}$ at $95{ }^{\circ} \mathrm{C}$ and 40 cycles of $15 \mathrm{~s}$ at $95{ }^{\circ} \mathrm{C}, 1 \mathrm{~min}$ at $55^{\circ} \mathrm{C}$ and $1 \mathrm{~min}$ at $72{ }^{\circ} \mathrm{C}$, followed by a melting curve. All qRT-PCR experiments were run in triplicate. The iCycler software (Bio-Rad) detected the threshold cycle (CT) for each amplicon. Normalization was performed using the 22DDC $\mathrm{T}$ method [35].

\section{RESULTS}

\section{Silica Nanoparticles}

No NP were formed at a $\mathrm{pH}$ of $<2$ or $>7$. Additionally, the proportion of oil to water had to be beyond 1:7 to allow for NP formation. For encapsulation of ACV, the optimum encapsulation parameters were a $\mathrm{pH}$ between 5-6 and a water:oil ratio of 1:10. TEM imaging of the resulting $\mathrm{SiO}_{2}$ NP showed that they were electron dense spheroids, with mean diameters of $25 \pm 5 \mathrm{~nm}$ (Fig. 1).

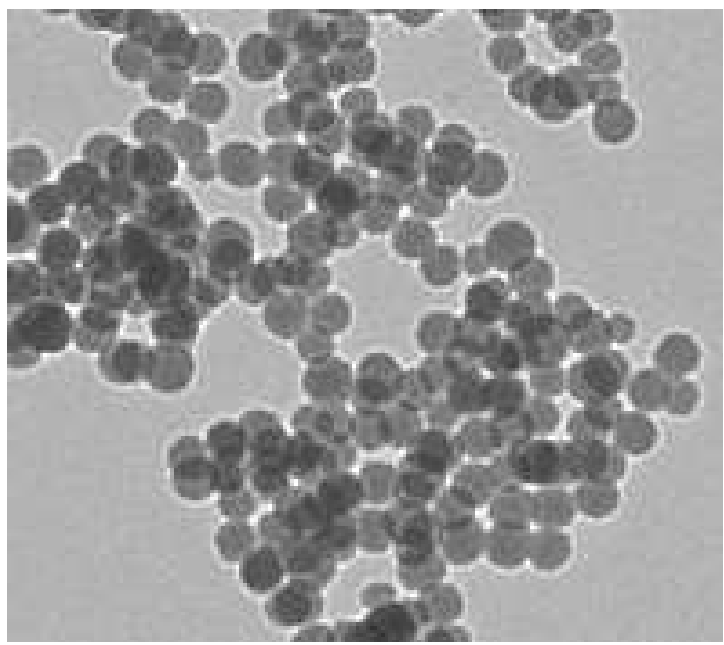

Fig. (1). TEM image of $\mathrm{SiO}_{2}$ nanoparticles, showing their spherical shape. Average diameter of particles is $25 \pm 5 \mathrm{~nm}$.

\section{Effects of $\mathrm{SiO}_{2}$ on Cell Viability}

Concentrations of $\mathrm{ACV}, \mathrm{SiO}_{2} \mathrm{NP}$, and $\mathrm{SiO}_{2}$ encapsulated $\mathrm{ACV}$ dispersed in culture medium did not have any cytopathic effects on cultured HCECs, up to $250 \mu \mathrm{g} / \mathrm{ml}$. At $500 \mu \mathrm{g} / \mathrm{ml}$, however, the NP aggregated and there was lifting of cells observed (live/dead staining and MTT; data not shown). TEM observations showed that the presence of NP, up to concentrations of $100 \mu \mathrm{g} / \mathrm{ml}$, mostly remained extracellular (Fig. 2A). The few NPs that were internalized were found in membrane-bound structures (Fig. 2B), e.g. lysosomes. However, the cell cytoplasm remained electron lucent with intact organelles, confirming that they were still healthy.

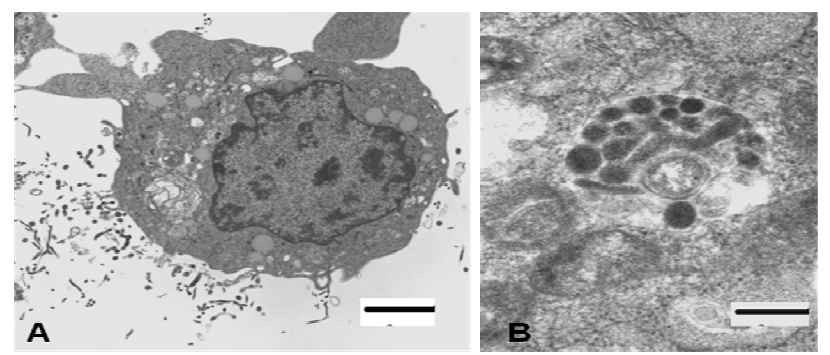

Fig. (2). Effects of $\mathrm{SiO}_{2}$ nanoparticles on cell viability. HCECs were incubated with $100 \mu \mathrm{g} / \mathrm{ml} \mathrm{SiO}_{2}$ and processed for transmission electron microscopy (TEM) to visualize uptake of NP, seen as electron dense spheres. Scale bars, A, $2 \mu \mathrm{m} ; \mathbf{B}, 200 \mathrm{~nm}$.

\section{Effect of $\mathrm{SiO}_{2}$ Nanoparticles on Hydrogel Transparency}

The incorporation of $\mathrm{SiO}_{2} \mathrm{NP}$ did not adversely affect the transmission of light through hydrogels (Table 1). Transmission values at all wavelengths tested was over $90 \%$, meeting the reported value of about $87 \%$ reported for healthy human corneas [36]. As our NP average about $25 \mathrm{~nm}$ in size, below the wavelength of visible light $(<280 \mathrm{~nm}$; sunlight has an averaged wavelength of $560 \mathrm{~nm}$ ), they do not cause perceptible light scattering and therefore do not affect transparency [37].

Table 1. Optical Properties of Biomimetic Corneas. CollagenMPC alone and Loaded with $\mathrm{SiO}_{2}$ NP were Measured for Transmission at Different Wavelengths of Visible Light $(450,500,550,600$ and $650 \mathrm{~nm})$

\begin{tabular}{|c|c|c|c|c|c|c|}
\hline Sample & \multicolumn{6}{|c|}{ Collagen-MPC } \\
\hline Wavelength(nm) & White & 450 & 500 & 550 & 600 & 650 \\
\hline Transmission(\%) & 91.6 & 99.7 & 99.6 & 99.4 & 98.8 & 97.4 \\
\hline Sample & \multicolumn{6}{|c|}{$\mathrm{SiO}_{2} \mathrm{NP}$ Dispered in Collagen-MPC } \\
\hline Wavelength(nm) & White & 450 & 500 & 550 & 600 & 650 \\
\hline Transmission(\%) & 95.7 & 92.7 & 99.6 & 99.4 & 98.8 & 97.4 \\
\hline
\end{tabular}

\section{Release of ACV from $\mathrm{SiO}_{2}$ Nanoparticles within Hydro- gels, and Bioactivity of Released ACV}

Free ACV incorporated within collagen-MPC hydrogels showed rapid and complete drug release after 2 days (Fig. 3). By comparison, $\mathrm{SiO}_{2}$ encapsulated $\mathrm{ACV}$ within collagenMPC hydrogels showed a gradual release over 12 days, shown by HPLC analysis.

HSV-1 viruses showed a statistically significant $(\mathrm{P}<0.05$; by ANOVA/Tukey tests) dose dependence response to ACV. At 1.0 to 1.5 and 2.0 to $2.5, \mathrm{SiO}_{2}$ encapsulated ACV showed significantly higher anti-viral activity, but it should be noted that the released ACV doses were slightly higher than the free ACV (Fig. 4). At the highest dose, where $3.5 \mu \mathrm{g} / \mathrm{ml}$ of 


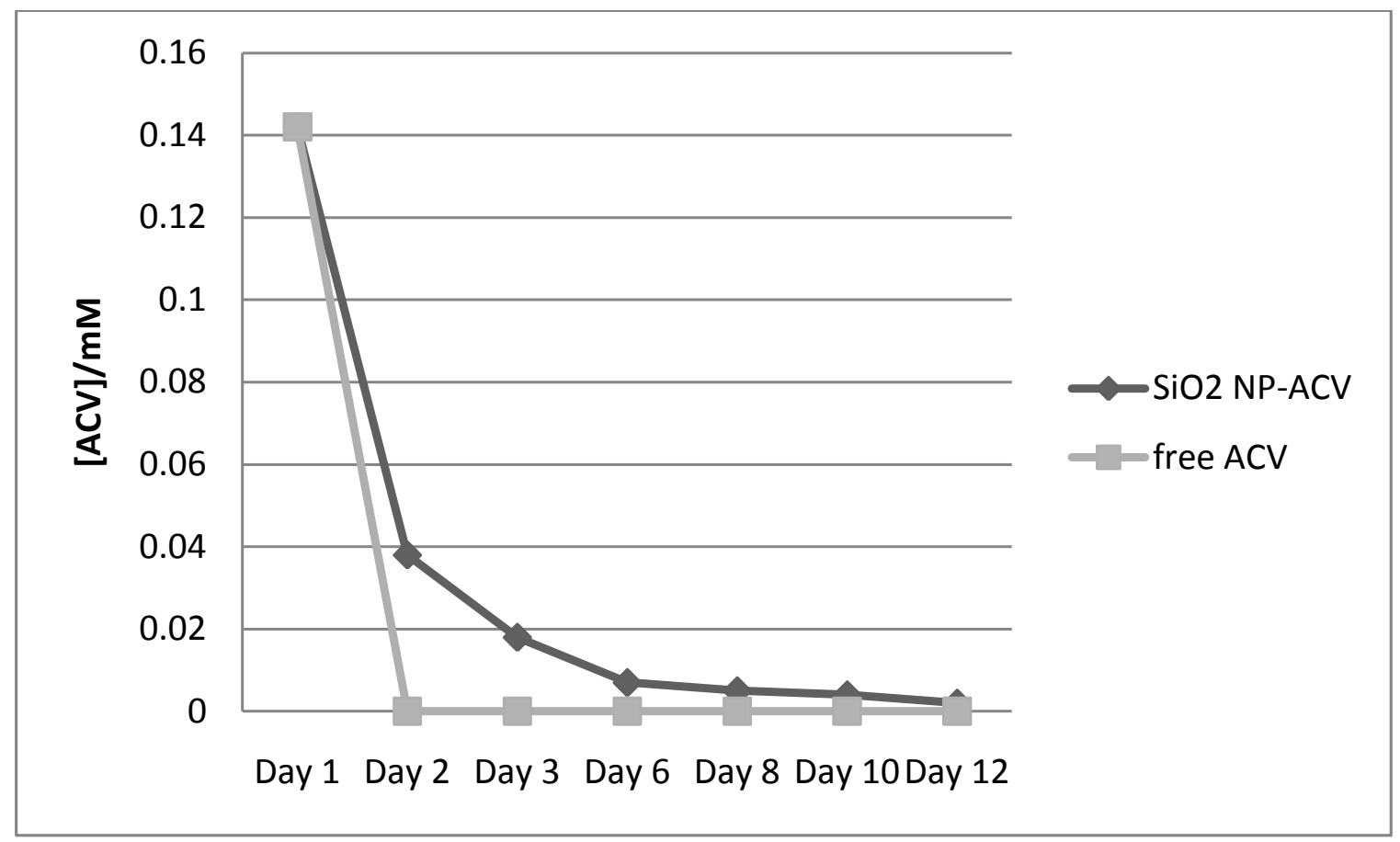

Fig. (3). Release profile of ACV encapsulated within $\mathrm{SiO}_{2}$ nanoparticles that have been incorporated into collagen-phosphorylcholine hydrogels compared with that of free ACV within the similar hydrogels, as determined by HPLC over the course of 12 days.

released $\mathrm{ACV}$ was compared to $4 \mu \mathrm{g} / \mathrm{ml}$ of free $\mathrm{ACV}$, the reverse was true (Fig. 4). Nevertheless, these results demonstrate fairly comparable efficacy between encapsulated and free drug, showing that the nanoparticle-encapsulated drug retained it full bioactivity.

Free ACV incorporated within collagen-MPC hydrogels showed rapid and complete drug release after 24 hours. By comparison, $\mathrm{SiO}_{2}$ encapsulated $\mathrm{ACV}$ within collagen-MPC hydrogels showed a gradual release over 12 days, as shown by an anti-viral assay (Fig. 5). Free ACV within the hydrogels was rapidly depleted, and thus had no effect on viral activity. In the free ACV case, the number of live cells remaining was not significantly different from those of untreated, infected cells after 24 hours. $\mathrm{SiO}_{2}$ encapsulated ACV within the hydrogels, however, was able to interfere with virus activity, and enhance cell survival until 10 days. Fig. (5C, D and E) demonstrate furthermore the cell morphology of healthy and HSV-infected cells.

\section{Effects of Released ACV in Reducing Viral Copies in Treated Cells: Real-Time PCR}

Real-time PCR runs showed that the relative expression of HSV was 7131-fold higher in untreated, virus-infected

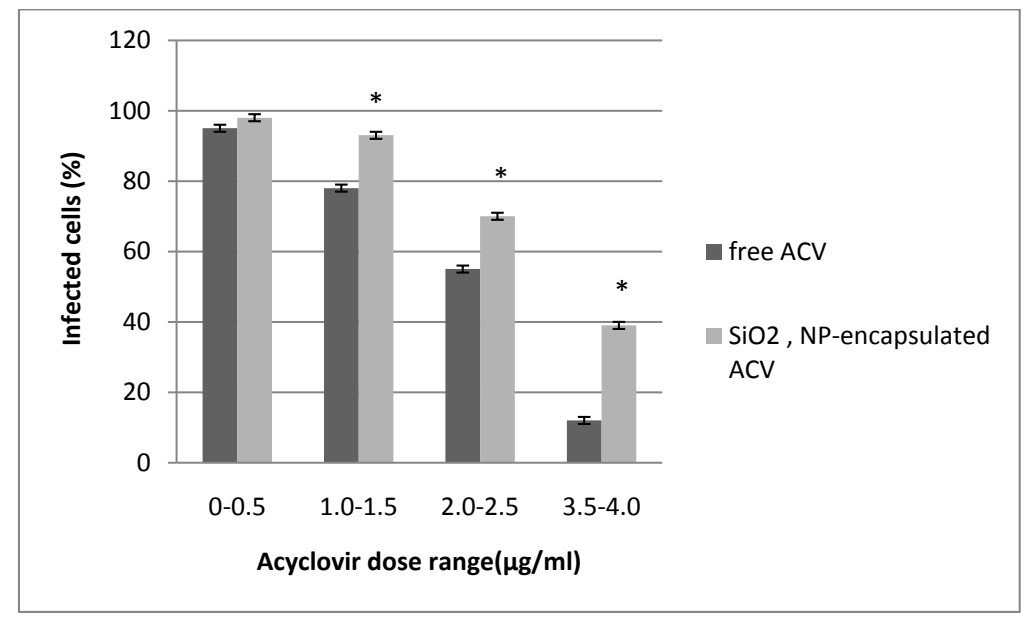

Fig. (4). Anti-HSV activity of $\mathrm{SiO}_{2}$ nanoparticle released ACV compared to comparable free ACV concentrations. There was residual unreleased ACV from the nanoparticle-encapsulated drug, so narrow dose ranges were compared instead of exact doses. * Indicates significant difference $(\mathrm{P}$ value $<0.001)$ from free ACV within one dosage range. 

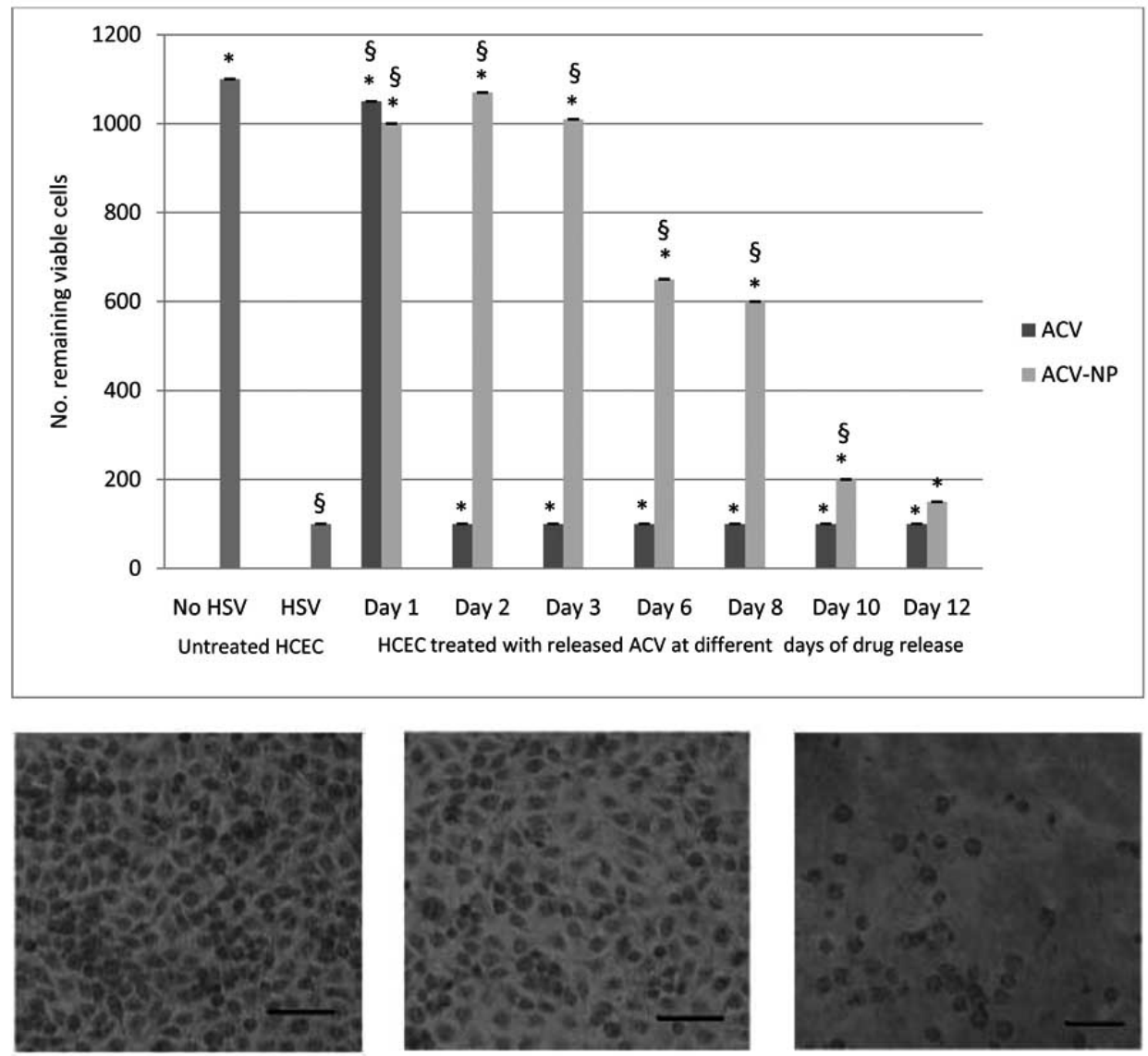

Fig. (5). A) Comparison of efficacy in inhibiting HSV-1 viruses of free $v s$. $\mathrm{SiO}_{2}$ nanoparticle-encapsulated ACV released from collagenMPC hydrogels over 12 days. Hydrogels were placed in PBS to allow release of ACV. At different time points after the start of release (days $1,2,3,6,8,10$ and 12) they were placed on top of corneal epithelial cells that were infected with $10^{4}$ pfu of HSV-1. Counts of surviving cells indicating efficacy of remaining ACV in the hydrogels at each time point were analysed by ANOVA followed by a Tukey-test. *, $\S$ indicates significant difference $(\mathrm{P}$ value $<0.001)$ between each sample and the negative control of uninfected HCEC, or positive control of HSV-1 infected, untreated HCEC, respectively. (B) Healthy, uninfected HCECs showing a flattened, cobble-stoned morphology when confluent. The same morphological appearance is observed for HSV-1 exposed cells treated with ACV in doses that block viral cytopathic activity (C). HSV-1 infected cells are rounded, with pyknotic nuclei that are typical of dying cells (D). Scale bars, $30 \mu \mathrm{m}$.

cells compared to uninfected cells (Table 2). Cells treated with ACV loaded directly into hydrogels showed a 1702-fold higher expression in HSV gene expression compared to uninfected cells, showing viral suppression by the drug. However, when infected cells were treated with ACV released from nanoparticles within the hydrogels, relative gene expression was only 1.78 fold higher than the uninfected cells. These data clearly demonstrates that prolonged ACV release from $\mathrm{SiO}_{2} \mathrm{NP}$ and hydrogel leads to a greater anti-HSV activity.

\section{DISCUSSION}

Our results show that $\mathrm{SiO}_{2} \mathrm{NP}$ produced by the water-oil microemulsion method can effectively encapsulate hydrophobic ACV, and release the drug in a sustained manner over 12 days. We also showed that $\mathrm{SiO}_{2} \mathrm{NP}$ are biocompatible and non-cytotoxic to HCECs in culture, up to concentrations of $250 \mu \mathrm{g} / \mathrm{ml}$. At $500 \mu \mathrm{g} / \mathrm{ml}$, some cytotoxic effects were observed that were presumably related to the observed clumping of the NP at higher concentrations. TEM
Table 2. RT-PCR Analysis of HSV Copies. HCEC without Virus (No Virus as Negative Control) was used to Normalize GAPDH Housekeeping Gene in all Samples. HSV-1 Primers were used to Determine Viral Copy Fold Changes in Samples Compared to Negative Control. As a Positive Control, Untreated HSV Infected Cells were used

\begin{tabular}{|c|c|c|c|c|}
\hline \multicolumn{5}{|c|}{ Fold change of qRT-PCR } \\
\hline & no virus & HSV untreated & $\begin{array}{c}\text { HSV + ACV } \\
\text { in hydrogel }\end{array}$ & $\begin{array}{c}\mathrm{HSV}+\mathrm{ACV}- \\
\mathrm{SiO}_{2} \text { in hydrogel }\end{array}$ \\
\hline HSV-1 & N/A & 7131 & 1702 & 1.78 \\
\hline GAPDH & 1 & 1 & 1 & 1 \\
\hline
\end{tabular}

observations showed that at a non-cytotoxic level of 100 $\mu \mathrm{g} / \mathrm{ml}$, most NP were localized external to the cell plasma membranes. Only a small number of particles were seen within membrane bound structures that resembled lysosomes. However, the cells in which these NP were localized still had electron lucent cytoplasm and intact organelles, indicative of healthy cells. 
When incorporated into collagen-MPC hydrogels, the NP did not impair optical clarity. On the contrary, implants with NP showed high light transmission (92.7-99.6\%) that was comparable to control hydrogels without NP (91.6-99.7\%). This was within the acceptable range of about $87 \%$ reported for human corneas [35]. The high optical clarity was most likely due to the small size of the 20-30 nm diameter particles, which are weakly interacting with light. However, we also found that the optical clarity is very dependent upon the dispersement of the NP, as NP aggregate scatter-light more efficient than suspensions of individual NP.

The release of free ACV incorporated into collagen-MPC hydrogels occurred over 2 days. Release of $\mathrm{SiO}_{2}$ NP-encapsulated ACV within collagen-MPC hydrogels, however, occurred over 12 days. In addition, the released ACV from hydrogel-NP constructs retained its bioactivity. These results show that this drug encapsulation method and the further incorporation into collagen-MPC hydrogels did not adversely affect ACV bioactivity.

Previous studies have shown very clearly that the use of micro- and nano-particulate carriers (e.g. PECA nanospheres in topical applications [36], Eudragit microparticles [26], or liposomes) [19]) have been successful in extending drug release time and therefore availability. However, in vivo applications are still proble-matic as both drugs and their carriers are rapidly cleared from the ocular surface by tearing and blinking. Hence, incorporation of carriers into a retentive ophthalmic ointment [19] or into contact lenses [22] have been proposed as means of extending drug availability to the ocular surface. However, to remedy HSV-induced vision loss, instead of treating the cornea with drugs and performing allograft surgery as two separate modalities, both with limited success rates, our results indicate that it would be possible to incorporate the drug/carrier directly into biosynthetic substitutes of human donor corneas $[11,12]$, to allow for the drug to be released after implantation to prevent viral re-activation and re-infection. Incorporating the drug into a graft would circumvent drug availability issues to all the corneal layers. Moreover, the presence of the drug at the time of surgery would serve a prophylactic function.

In the present study, nanoparticle-encapsulated ACV released from collagen-MPC hydrogels that we previously designed as corneal substitutes [12] showed sufficient antiviral activity, even after 10 days of continuous release, to significantly increase the viability of cultured human corneal epithelial cells that were infected with HSV-1 viruses. Correspondingly, real-time PCR showed that the sustained release of ACV was able to block HSV-1 infection of corneal epithelial cells in culture, as evidenced by the extremely low viral copies within treated corneal cells (Table 2).

Although further optimization (e.g. change in drug carrier, size of the carrier, drug incorporation method, most appropriate anti-viral drug/prodrug) is required to maximize the sustained release of drug and treatment efficacy, we have nevertheless demonstrated the feasibility of incorporation of a drug-release system into corneal substitutes designed as alternatives to donor human tissues for corneal transplantation of HSV-infected eyes. With future development, this could become one method to counter potential HSVreactivation, triggered by the stress induced by the transplantation procedure and post-operative steroid treatment.

\section{ACKNOWLEDGEMENTS}

We thank Ms. Subhadra Dravida for technical support and Dr. Yun Liu of Centre for Catalysis Research and Innovation (CCRI), University of Ottawa and Mr. Peter Rippstein at the University of Ottawa Heart Institute for TEM imaging support. Funding for this study is from a collaborative health research project grant from NSERC and CIHR to May Griffith, James L. Harden and Juan C. Scaiano.

\section{REFERENCES}

[1] Liesegang TJ. Herpes simplex virus epidemiology and ocular importance. Cornea 2001;20(1): 1-13.

[2] Liesegang TJ, Melton LJ, 3rd, Daly PJ, Ilstrup DM. Epidemiology of ocular herpes simplex. Incidence in Rochester, Minn, 1950 through 1982. Arch Ophthalmol 1989; 107(8): 1155-9.

[3] Miserocchi E, Modorati G, Galli L, Rama P. Efficacy of valacyclovir $v s$. acyclovir for the prevention of recurrent herpes simplex virus eye disease: a pilot study. Am J Ophthalmol 2007; 144(4): 547-51.

[4] Toma HS, Murina AT, Areaux RG, Jr., et al. Ocular HSV-1 latency, reactivation and recurrent disease. Semin Ophthalmol 2008; 23(4): 249-73.

[5] Khan BF, Pavan-Langston D. Clinical manifestations and treatment modalities in herpes simplex virus of the ocular anterior segment. Int Ophthalmol Clin 2004; 44(3): 103-33.

[6] Balfour HH, Jr. Antiviral drugs. N Engl J Med 1999; 340(16): 1255-68.

[7] Pevenstein SR, Williams RK, McChesney D, Mont EK, Smialek JE, Straus SE. Quantitation of latent varicella-zoster virus and herpes simplex virus genomes in human trigeminal ganglia. J Virol 1999; 73(12): 10514-8.

[8] Shimomura YDT, Fukuda M, Higaki S, Hooper LC, Hayashi K. Corneal buttons obtained from patients with HSK harbor high copy numbers of the HSV genome. Cornea 2007; 26(2): 190.

[9] Liu W, Merrett K, Griffith M, et al. Recombinant human collagen for tissue engineered corneal substitutes. Biomaterials 2008; 29(9): 1147-58.

[10] Merrett K, Fagerholm P, McLaughlin CR, et al. Tissue-engineered recombinant human collagen-based corneal substitutes for implantation: performance of type I versus type III collagen. Invest Ophthalmol Vis Sci 2008; 49(9): 3887-94.

[11] Fagerholm PLN, Carlsson DJ, Merrett K, Griffith M. Corneal regeneration following implantation of a biomimetic tissueengineered substitute. Clin Transl Sci 2009; 2(2): 162-4.

[12] Liu WDC, McLaughlin CR, Fagerholm P, et al. Collagenphosphorylcholine interpenetrating network hydrogels as corneal substitutes. Biomaterials 2009; 30(8).

[13] Snoeck RDE. Treatment of herpes simplex virus infections. Infect Med 1999; 16: 249-65.

[14] Bourlais CL, Acar L, Zia H, Sado PA, Needham T, Leverge R. Ophthalmic drug delivery systems--recent advances. Prog Retin Eye Res 1998; 17(1): 33-58.

[15] O'Brien JJ, Campoli-Richards DM. Acyclovir. An updated review of its antiviral activity, pharmacokinetic properties and therapeutic efficacy. Drugs 1989; 37(3): 233-309.

[16] Nagarsenker MS, Londhe VY, Nadkarni GD. Preparation and evaluation of liposomal formulations of tropicamide for ocular delivery. Int J Pharm 1999; 190(1): 63-71.

[17] Gulsen D, Chauhan A. Ophthalmic drug delivery through contact lenses. Investig Ophthalmol Vis Sci 2004; 45(7): 2342-7.

[18] Richards DM, Carmine AA, Brogden RN, Heel RC, Speight TM, Avery GS. Acyclovir. A review of its pharmacodynamic properties and therapeutic efficacy. Drugs 1983; 26(5): 378-438.

[19] Chetoni P, Rossi S, Burgalassi S, Monti D, Mariotti S, Saettone MF. Comparison of liposome-encapsulated acyclovir with acyclovir 
ointment: ocular pharmacokinetics in rabbits. J Ocul Pharmacol Ther 2004; 20(2): 169-77.

[20] Kreuter J. Nanoparticles as bioadhesive ocular drug delivery systems. In: Lenaerts V GR, Ed. Bioadhesive Drug Delivery Systems. Boca Raton: CRC Press 1990; pp. 203-12.

[21] Marcato PD, Duran N. New aspects of nanopharmaceutical delivery systems. J Nanosci Nanotechnol 2008; 8(5): 2216-29.

[22] Aznar AJ, Gutiérrez P, Diaz P, Alvarez A, Poncelet G. Silica from sepiolite: preparation, textural properties, and use as support to catalyst. Microporous Mater 1996; 6: 105-14.

[23] Ikeue KNS, Ogawa M, Anpo M. Characterization of selfstanding Ti-containing porous silica thin films and their reactivity for the photocatalytic reduction of $\mathrm{CO}_{2}$ with $\mathrm{H}_{2} \mathrm{O}$. Catal Today 2002; 74 : 241-8.

[24] Kosuge KSK, Tsunashima A. Micropore formation by acid treatment of antigorite. Chem Mater 1995; 7: 2241-6.

[25] Liu Y ZL, Yao X, Xu CN. Development of porous silica thick films by a new base-catalyzed sol-gel route. Mater Lett 2001; 49: 102-7.

[26] Shinoda TOM, Izumi Y. Proposed models of mesopore structures in sulfuric acid-treated montmorillonites and K10. Chem Lett 1995; 7: 495-6.

[27] Temuujin JOK, MacKenzie KJD. Characterization of porous silica prepared from mechanicallyamorphized kaolinite by selective leaching. Powder Technol 2001; 121: 259-62.

[28] Temuujin JOK, MacKenzie KJD. Preparation of porous silica from vermiculite by selective leaching. Appl Clay Sci 2003; 22: 187-95.
[29] Osseo-Asare KAF. Preparation of $\mathrm{SiO}_{2}$ Nanoparticles in a NonIonic Reverse Micellar System. Colloids Surf 1990; 50: 321-39.

[30] Osseo-Asare KAF. Growth kinetics of nanosize silica in a nonionic water-in-oil microemulsion: a reverse micellar pseudophase reaction model. J Colloid Interface Sci 1999; 218(1): 68-76.

[31] Yamauchi HIT, Kondo S. Surface characterization of ultramicro spherical particles of silica prepared by W/O microemulsion. Colloids Surf 1989; 37: 71-80.

[32] Araki-Sasaki KOY, Sasabe T. An SV-40 immortalized human corneal epithelial cell line and its cheracterization. Invest Opthalmol Vis Sci 1995; 36: 614-21.

[33] Ngamwongsatit PBP, Panbangred W, Bhunia AK. WSt-1 based cell cytotoxity assay as a substitute for MTT-based assay for rapid detection of toxigenic Bacillus species using $\mathrm{CHO}$ cell line. J Microbiol Methods 2008; 73: 211-5.

[34] Priest DMR. A new instrument for monitoring the optical properties of corneas. Invest Opthalmol Vis Sci 1998; 39(Suppl): s352.

[35] Livak KJ, Schmittgen TD. Analysis of relative gene expression data using real-time quantitative PCR and the 2(-Delta Delta C(T)). Method. Methods 2001; 25: 402-8.

[36] Beems EM, Van Best JA. Light transmission of the cornea in whole human eyes. Exp Eye Res 1990; 50(4): 393-5.

[37] Fresta M, Fontana G, Bucolo C, Cavallaro G, Giammona G, Puglisi G. Ocular tolerability and in vivo bioavailability of poly(ethylene glycol) (PEG)-coated polyethyl-2-cyanoacrylate nanosphereencapsulated acyclovir. J Pharm Sci 2001; 90(3): 288-97.

(C) Bareiss et al.; Licensee Bentham Open.

This is an open access article licensed under the terms of the Creative Commons Attribution Non-Commercial License (http://creativecommons.org/ licenses/by-nc/3.0/), which permits unrestricted, non-commercial use, distribution and reproduction in any medium, provided the work is properly cited. 